\title{
The Development of Vertebral Deformities in a Preschool Child with Dysplastic Spondylolisthesis: A 16-Year Follow-Up
}

\section{Masayuki Ohashi ${ }^{*}$, Toru Hirano ${ }^{1}$, Naoto Endo ${ }^{1}$ and Seiji Uchiyama²}

${ }^{1}$ Division of Orthopaedic Surgery, Department of Regenerative and Transplant Medicine, Niigata University Graduate School of Medical and Dental Sciences, Niigata, Japan ${ }^{2}$ Department of Orthopaedic Surgery, Nishi-Niigata Chuo National Hospital, Niigata, Japan

\begin{abstract}
Study design: A case report describing the development of vertebral deformities associated with dysplastic spondylolisthesis that was managed conservatively until skeletal maturity was achieved.
\end{abstract}

Objective: To describe development of wedging and rounding vertebral deformities.

Summary of Background Data: There are no reports of preschool children with dysplastic spondylolisthesis that were managed conservatively until skeletal maturity.

Methods: A 5-year-old girl presented with a postural deformity associated with congenital scoliosis and dysplastic spondylolisthesis. Surgery was performed for scoliosis at the age of 13 years, but spondylolisthesis was managed conservatively up to skeletal maturity.

Results: The wedging of the L5 body and the rounding of the sacrum progressed during her growth period, and no progression was observed thereafter. The slippage progressed gradually during and after her growth period, and posterior lumbar interbody fusion was performed at the age of 21 years.

Conclusion: We speculate that the slippage associated with dysplastic spondylolisthesis occurs at the growth plate, and vertebral deformities are the results rather than the causative factors of the slippage as observed in the case of slippage associated with isthmic spondylolisthesis.

Keywords: Dysplastic spondylolisthesis; Vertebral deformity; Development of deformity; Wedging deformity; Rounding deformity; Posterior lumbar interbody fusion

\section{Introduction}

Dysplastic spondylolisthesis is defined as spondylolisthesis secondary to congenital abnormalities of the lumbosacral articulation, including maloriented or hypoplastic facets and sacral deficiency [1]. Dysplastic spondylolisthesis is characterized by wedging of the L5 body and a rounding deformation of the sacrum surface on radiography [2]; further, it has been suggested that these 2 anatomic factors play an important role in the development of a slip [3-5]. However, some authors have stated that these changes should be considered as the consequences rather than the causes of the olisthetic process in adolescents with spondylolysis [6-10].

The dysplastic type is less common, and symptomatic patients usually require surgical treatment at a relatively early age because the natural history of this condition is progressive [3,11-14]. Therefore, there are no reports of preschool children with dysplastic spondylolisthesis that has been managed conservatively until skeletal maturity was achieved. For this reason, it is controversial whether vertebral deformities such as wedging of the L5 body and rounding deformation of the sacrum surface are the consequences or causes of the olisthetic process in dysplastic spondylolisthesis.

We report the 16-year follow-up of a 5-year-old with dysplastic spondylolisthesis who did not exhibit vertebral deformities at the first radiologic examination.

\section{Case Report}

A 5-year-old girl presented with a postural deformity. She was diagnosed at birth with Treacher Collins syndrome, a form of the spectrum of mandibulofacial dysostoses. She was neurologically intact and had no back pain. A radiograph of the thoracic spine revealed a right congenital scoliosis that measured $47^{\circ}$ with a unilateral unsegmented bar (Figure 1). In addition to the thoracic deformity, lumbar radiographs revealed lumbosacral spondylolisthesis. The horizontal facets of the lumbosacral junction were observed in the

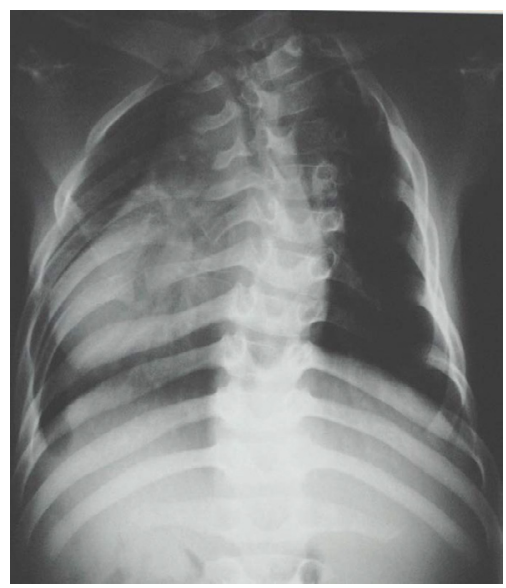

Figure 1: The anteroposterior radiograph of the thoracic spine at 5 years of age showing right congenital scoliosis with an unsegmented bar.

*Corresponding author: Masayuki Ohashi, Division of Orthopaedic Surgery, Department of Regenerative and Transplant Medicine, Niigata University Graduate School of Medical and Dental Sciences 1-757 Asahimachi Dori Niigata City 951-8510, Japan, Tel: +81-25-227-2272; Fax: +81-25-227-0782; E-mail: masayuki-ohashi@ksh.biglobe.ne.jp

Received January 16, 2014; Accepted February 03, 2014; Published February 06, 2014

Citation: Ohashi M, Hirano T, Endo N, Uchiyama S (2014) The Development of Vertebral Deformities in a Preschool Child with Dysplastic Spondylolisthesis: A 16Year Follow-Up. J Spine 3: 156. doi:10.4172/2165-7939.1000156

Copyright: $\odot 2014$ Ohashi M, et al. This is an open-access article distributed unde the terms of the Creative Commons Attribution License, which permits unrestricted use, distribution, and reproduction in any medium, provided the original author and source are credited. 
Citation: Ohashi M, Hirano T, Endo N, Uchiyama S (2014) The Development of Vertebral Deformities in a Preschool Child with Dysplastic Spondylolisthesis: A 16-Year Follow-Up. J Spine 3: 156. doi:10.4172/2165-7939.1000156

anteroposterior view (Figure 2A), and the lateral view did not reveal spondylolysis (Figure 2B). Therefore, we diagnosed the condition as dysplastic spondylolisthesis. The percentage of the slip was $40 \%$ (Meyerding grade [8] was grade 2), and the lumbar index was $100 \%$. The rounding deformation of the sacrum surface was not indicated (rounding index was $0 \%$ ). These parameters were measured on a standing lateral roentgenogram according to the method described by Boxall et al. [4] and Wiltse and Winter [15].

The patient required operative treatment for scoliosis at the age of 13 years. Preoperative standing radiographs revealed thoracic scoliosis that measured $123^{\circ}$. Posterior spinal fusion from C7 to T10 with instrumentation was performed, and thoracic scoliosis was corrected to $86^{\circ}$.

Clinical observation with radiographic examinations was chosen for dysplastic spondylolisthesis because the patient was free of symptoms and was at risk for general anesthesia complications due to mandibular hypoplasia, one of the anomalies associated with Treacher Collins syndrome.

Her body height and the development of the slippage and vertebral deformities such as wedging of the L5 body and rounding of the sacrum surface are shown in Figure 3. Her body height was $104 \mathrm{~cm}$ at the age of
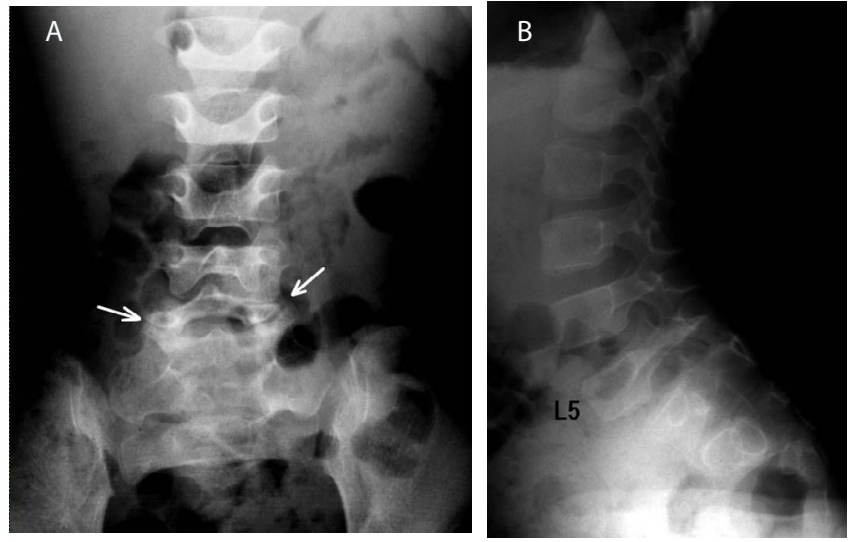

Figure 2: Lumbar radiographs at 5 years of age

A. The anteroposterior radiograph showing the horizontal facets of the lumbosacral junction (arrows).

B. The lateral radiograph showing spondylolisthesis of L5 without spondylolysis and vertebral deformities.

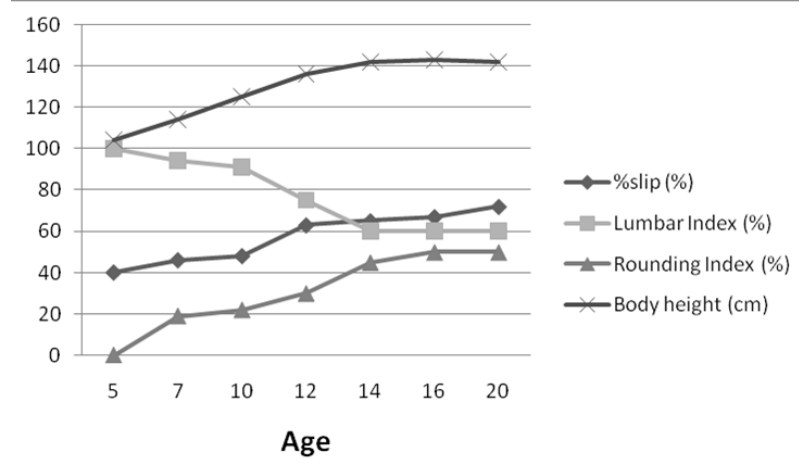

Figure 3: The graph shows an increase in body height and development of the slippage and vertebral deformities such as wedging of the L5 body and rounding deformation of the sacrum surface. The slippage and vertebral deformities progressed during her growth period. Thereafter, vertebral deformities remained constant and the slippage slowly progressed.
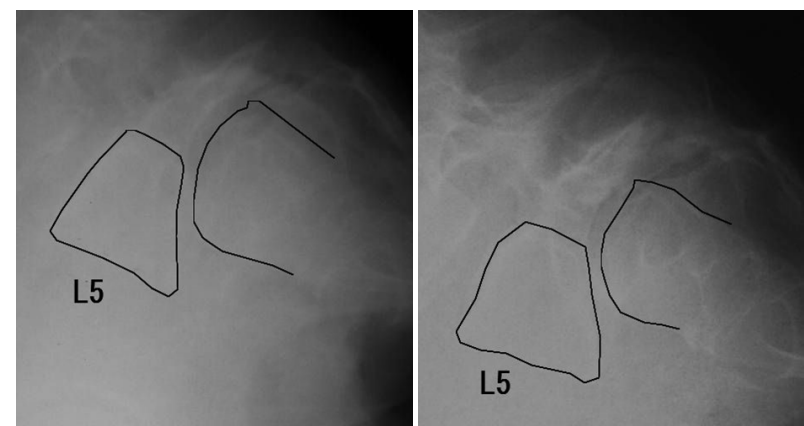

Figure 4: Lateral lumbar radiographs

The tracing indicates the outline of L5 and S1 vertebral bodies.

A. The radiograph at 14 years of age showing $65 \%$ slippage, a lumbar index of $60 \%$, and a rounding index of $45 \%$.

B. The radiograph at 20 years of age showing $72 \%$ slippage, a lumbar index of $60 \%$, and a rounding index of $50 \%$.

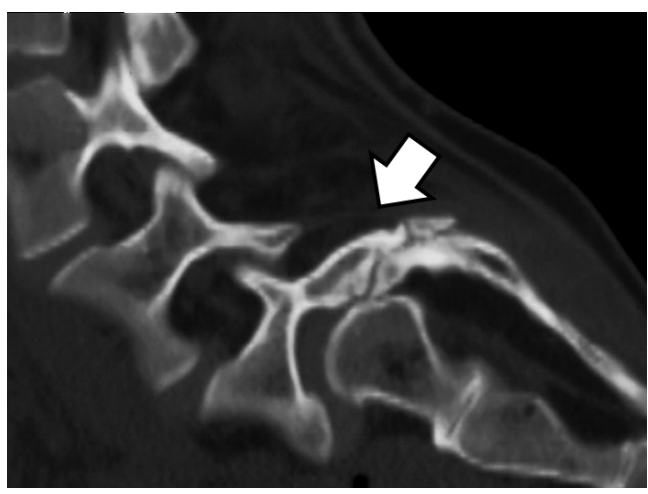

Figure 5: The computed tomography scan at 20 years of age showing subluxation of the right L5/S1 facets (arrow). The same finding is observed on the left side.

5 years and increased to $142 \mathrm{~cm}$ up to the age of 14 years, after which it remained constant. The percentage of the slip increased up to 14 years and was $65 \%$ (Meyerding grade 3 ). Thereafter, it gradually increased and was $72 \%$ (Meyerding grade 3 ) at 20 years of age. The lumbar index decreased before she reached the age of 14 years; thereafter, radiographs showed a constant lumbar index of approximately $60^{\circ}$. The rounding index increased up to 14 years of age and thereafter remained constant at approximately $50 \%$ as determined by radiography (Figures $2 \mathrm{~B}$ and 4). All these parameters progressed dramatically between the ages of 10 and 14 years, i.e., her growth period.

At the age of 20 years, she presented with progressive lower back pain and bilateral thigh pain, and surgery was performed at the age of 21 years. A computed tomography (CT) scan revealed subluxation of the bilateral L5/S1 facets (Figure 5). The operation was conducted with the patient in the prone position on an operating table. Pedicle screws were placed in the pedicles of L5 and S1. Next, L5 laminectomy was performed, and the inferior articular facets of L5 and the superior articular facets of S1 were removed. The reduction of the anterior slippage of L5 and posterior lumbar interbody fusion with titanium cages were then performed. The percentage of the slip was corrected to 16\% (Meyerding grade 1, Figure 6).

The patient had no postoperative motor and sensory deficits, and the treatment resulted in complete pain relief. A CT scan at 3 years after the surgery showed complete fusion without a loss of correction, and the patient has remained asymptomatic. 
Citation: Ohashi M, Hirano T, Endo N, Uchiyama S (2014) The Development of Vertebral Deformities in a Preschool Child with Dysplastic Spondylolisthesis: A 16-Year Follow-Up. J Spine 3: 156. doi:10.4172/2165-7939.1000156

Page 3 of 3

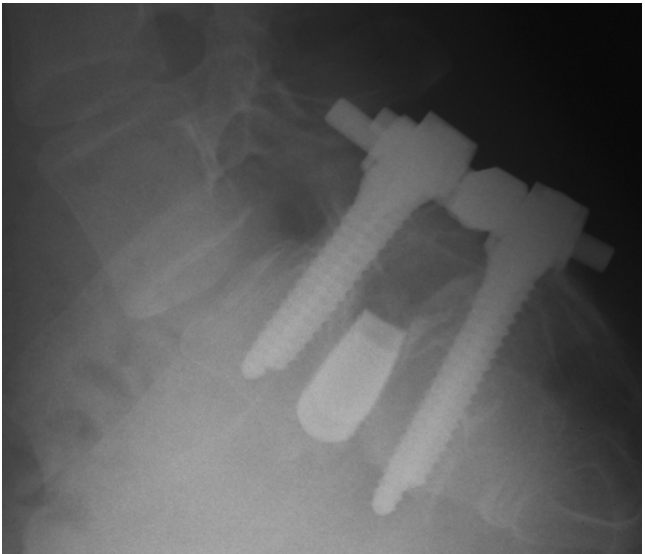

Figure 6: The postoperative lumbar radiograph. The percentage of the slip was corrected to $16 \%$

\section{Discussion}

Isthmic spondylolisthesis is reported to be prevalent in the growth period $[11,16,17]$ and very rarely occurs thereafter. In order to explain the prevalence of slippage in children, Farfan et al. [18] speculated that slippage results mainly from an epiphyseal separation. Some clinical and biomechanical studies have provided further evidence that slippage occurs at the growth plate, and wedging of the L5 body and rounding of the sacrum surface, which are well-known deformities associated with isthmic spondylolisthesis, are the results of the slippage rather than the causative factors $[6,7,9,19-21]$.

The dysplastic type is less common and constitutes $14-21 \%$ of the cases in a large series [4,22]. The patients with dysplastic spondylolisthesis are notably more likely to exhibit vertebral deformities at the first radiologic examination and require surgical treatment at an early age because the natural history of this condition is much more progressive than that of the spondylolytic type [3,11-14]. Therefore, there have been only 3 published reports on patients who were treated conservatively $[4,23,24]$. However, in these reports, the age of the patients at the initial examination ranged from 8 years to the mid-teens, and vertebral deformities such as wedging of the L5 vertebral body and rounding of the sacrum surface were already observed in their first radiographs. Therefore, there are no reports of preschool children with dysplastic spondylolisthesis that was treated conservatively up to skeletal maturity and who did not exhibit the abovementioned vertebral deformities at the first examination. Thus, it is controversial whether vertebral deformities are the results or the causative factors of the slippage.

In our case, radiographs showed spondylolisthesis with $40 \%$ slip, a lumbar index of $100 \%$, and a rounding index of $0 \%$; further, wedging of the L5 body and rounding deformation of the sacrum were not indicated when our patient was initially examined at the age of 5 years. The slippage developed from $40 \%$ to $60 \%$ during her growth period, and thereafter increased more gradually. The wedging of the L5 body and the rounding of the sacrum progressed during her growth period and did not progress thereafter. This suggests that the slippage associated with dysplastic spondylolisthesis also occurs at the growth plate, and wedging of the L5 body and rounding of the sacrum surface are the results of the slippage rather than the causative factors as observed in the case of slippage associated with isthmic spondylolisthesis. However, more cases would be required to provide further evidence.

\section{References}

1. Wiltse LL, Newman PH, Macnab I (1976) Classification of spondylolisis and spondylolisthesis. Clin Orthop Relat Res : 23-29.

2. Hammerberg KW (2005) New concepts on the pathogenesis and classification of spondylolisthesis. Spine (Phila Pa 1976) 30: S4-11.

3. Hensinger RN (1989) Spondylolysis and spondylolisthesis in children and adolescents. J Bone Joint Surg Am 71: 1098-1107.

4. Boxall D, Bradford DS, Winter RB, Moe JH (1979) Management of severe spondylolisthesis in children and adolescents. J Bone Joint Surg Am 61: 479495.

5. Blackburne JS, Velikas EP (1977) Spondylolisthesis in children and adolescents. J Bone Joint Surg Br 59-59B: 490-4.

6. Ikata T, Miyake R, Katoh S, Morita T, Murase M (1996) Pathogenesis of sports-related spondylolisthesis in adolescents. Radiographic and magnetic resonance imaging study. Am J Sports Med 24: 94-98.

7. Kajiura K, Katoh S, Sairyo K, Ikata T, Goel VK, et al. (2001) Slippage mechanism of pediatric spondylolysis: biomechanical study using immature calf spines. Spine (Phila Pa 1976) 26: 2208-2212.

8. Meyerding HW (1932) Spondylolisthesis. Surg Gynec and Obstet 54: 371-377

9. Sakamaki T, Sairyo K, Katoh S, Endo H, Komatsubara S, et al. (2003) The pathogenesis of slippage and deformity in the pediatric lumbar spine: a radiographic and histologic study using a new rat in vivo model. Spine (Phila Pa 1976) 28: 645-650.

10. Higashino K, Sairyo K, Sakamaki T, Komatsubara S, Yukata K, et al. (2007) Vertebral rounding deformity in pediatric spondylolisthesis occurs due to deficient of endochondral ossification of the growth plate. Radiological, histological and immunohistochemical analysis of a rat spondylolisthesis model. Spine 32: 2839-2845.

11. Fredrickson BE, Baker D, McHolick WJ, Yuan HA, Lubicky JP (1984) The natural history of spondylolysis and spondylolisthesis. J Bone Joint Surg Am 66: 699-707.

12. Freeman BL 3rd, Donati NL (1989) Spinal arthrodesis for severe spondylolisthesis in children and adolescents. A long-term follow-up study. J Bone Joint Surg Am 71: 594-598.

13. LAURENT LE, EINOLAS (1961) Spondylolisthesis in children and adolescents. Acta Orthop Scand 31: 45-64.

14. Velikas EP, Blackburne JS (1981) Surgical treatment of spondylolisthesis in children and adolescents. J Bone Joint Surg Br 63-63B: 67-70.

15. Wiltse LL, Winter RB (1983) Terminology and measurement of spondylolisthesis. J Bone Joint Surg Am 65: 768-772.

16. Dandy DJ, Shannon MJ (1971) Lumbo-sacral subluxation. (Group 1 spondylolisthesis). J Bone Joint Surg Br 53: 578-595.

17. Seitsalo S, Osterman K, Hyvãrinen H, Tallroth K, Schlenzka D, et al. (1991) Progression of spondylolisthesis in children and adolescents. A long-term follow-up of 272 patients. Spine (Phila Pa 1976) 16: 417-421.

18. Farfan HF, Osteria V, Lamy C (1976) The mechanical etiology of spondylolysis and spondylolisthesis. Clin Orthop Relat Res : 40-55

19. Sairyo K, Katoh S, Ikata T, Fujii K, Kajiura K, et al. (2001) Development of spondylolytic olisthesis in adolescents. Spine J 1: 171-175.

20. Konz RJ, Goel VK, Grobler LJ, Grosland NM, Spratt KF, et al. (2001) The pathomechanism of spondylolytic spondylolisthesis in immature primate lumbar spines in vitro and finite element assessments. Spine (Phila Pa 1976) 26: E38-49.

21. Sairyo K, Goel VK, Grobler LJ, Ikata T, Katoh S (1998) The pathomechanism of isthmic lumbar spondylolisthesis. A biomechanical study in immature calf spines. Spine (Phila Pa 1976) 23: 1442-1446.

22. Newman PH (1963) The etiology of spondylolisthesis. J Bone Joint Surg Br 45: 39-59.

23. Harris IE, Weinstein SL (1987) Long-term follow-up of patients with grade-III and IV spondylolisthesis. Treatment with and without posterior fusion. J Bone Joint Surg Am 69: 960-969.

24. Sha N, Doita M, Uno K, Yoshiya S, Kurosaka M (2004) Spontaneously stabilized severe dysplastic spondylolisthesis without operation: long-term follow-up of a preteenage patient. J Spinal Disord Tech 17: 451-455. 